\section{SURGICAL MANAGEMENT OF INFECTIVE ENDOCARDITIS ASSOCIATED WITH CEREBRAL COMPLICATIONS}

\section{Multi-center retrospective study in Japan}

To establish guidelines for the surgical treatment of patients with infective endocarditis who have cerebrovascular complications, we conducted a detailed retrospective study of 181 of 244 patients with cerebral complications among 2523 surgical cases of infective endocarditis of the Japanese Association of Thoracic Surgery. The results showed that $9.7 \%$ of all patients with infective endocarditis had associated cerebral complications: $108(44.3 \%)$ had active native valve endocarditis, $96(39.3 \%)$ had healed native valve endocarditis, and $40(16.4 \%)$ had prosthetic valve endocarditis. The hospital mortality of the patients with cerebral complications was $11.0 \%$ in the group as a whole: $13.9 \%$ in active native valve endocarditis, $3.1 \%$ in healed native valve endocarditis, and $37.5 \%$ in prosthetic valve endocarditis. Diseased valves included the following: aortic valve in $55.5 \%$, mitral valve in $49.8 \%$, tricuspid valve in $1.3 \%$, and pulmonary valve in $1.3 \%$. In 181 patients with cerebral complications, organisms were detected as follows: gram-positive cocci in 133 (73.5\% [Streptococcus in 85, Staphylococcus in 32]), gram-negative in 18 (9.9\%), fungus in $11(6.1 \%)$, and unknown in $19(\mathbf{1 0 . 5 \%})$. Types of cerebral complications included cerebral infarction in $64.6 \%$, cerebral bleeding in $31.5 \%$, cerebral abscess in $2.8 \%$, and meningitis in $1.1 \%$. Hospital mortality rate and an exacerbation rate of cerebral complications, including related death, according to the interval from onset of cerebral infarction to cardiac surgery, were as follows: $66.3 \%$ and $45.5 \%$ within 24 hours, 31.3\% and $43.8 \%$ between 2 and 7 days, $16.7 \%$ and $16.7 \%$ between 8 and 14 days, $10.0 \%$ and $10.0 \%$ between 15 and 21 days, $26.3 \%$ and $10.5 \%$ between 22 and 28 days, and $7.0 \%$ and $2.3 \%$ over 4 weeks later, respectively. A significant correlation existed between the interval and the exacerbation of cerebral complications (tied $p=0.008$ ). Preoperative risk factors affecting exacerbation of cerebral complications were as follows: (1) severity of cerebral complication $(p=0.006)$, (2) intervals $(p=0.012)$, and (3) uncontrolled congestive heart failure as indications for cardiac surgery $(p=0.014)$. One patient underwent a cardiac operation within 24 hours of the onset of cerebral hemorrhage and died of cerebral damage. No exacerbations occurred in 10 patients who underwent their operation between 2 and 28 days. Nevertheless, exacerbations oc $_{\text {m }}$ curred in $19.0 \%$ of patients whose operation was done more than 4 weeks later. These data suggest that cardiac operations can be done safely 4 weeks after cerebral infarction, and if the delay is more than 2 weeks, the

Kiyoyuki Eishi, MD, Kouhei Kawazoe, MD, Yoshihiro Kuriyama, MD, Yoshitsugu Kitoh, MD, Yasunaru Kawashima, MD, and Teruo Omae, MD, Osaka, Japan, for the 174 centers of the Japanese Association of Thoracic Surgery
From the Division of Cardiovascular Surgery, Division of Neurology, National Cardiovascular Center of Japan, Osaka, Japan. Supported in part by a grant for research on cardiovascular diseases from the Ministry of Health and Welfare, Japan.

Received for publication Dec. 23, 1994.

Accepted for publication April 19, 1995.
Address for reprints: Kiyoyuki Eishi, MD, Division of Cardiovascular Surgery, National Cardiovascular Center of Japan, 5-7-1 Fujishiro-dai, Suita, Osaka 565, Japan.

J THORAC CARDIOVASC SURG 1995;110:1745-55

Copyright $(1) 1995$ by Mosby-Year Book, Inc. 
exacerbation rate will be around $10 \%$. The risk of progression of cerebral damage is still significant 15 days and even 4 weeks after cerebral hemorrhage. (J Thorac Cardiovasc Surg 1995;110:1745-55)

$\mathrm{T}^{\mathrm{h}}$ he best means of treating patients with infective endocarditis who have various complications such as severe congestive heart failure, intramyocardial abscesses, sepsis, major embolization, or cerebral aneurysm is the subject of controversy. In the past decade, early surgical treatment has been recommended even during the active stage before progression of the lesions. ${ }^{1-3}$ In patients with cerebrovascular complications, however, a surgical approach to the cardiac lesion still involves several unsolved problems. ${ }^{4-11}$ A major concern is the timing of cardiac surgery in these patients, because cardiopulmonary bypass with unusual hypotension and total heparinization would amplify the cerebral ischemic damage and hemorrhage. ${ }^{8}$ Several groups, ours included, have tried to clarify the safety period between the cerebrovascular event and the cardiac operation, instead of limiting the number of patients with cerebral complications in each group. ${ }^{5,8-10}$ To establish the surgical treatment of patients with infective endocarditis associated with cerebrovascular complications, we conducted a detailed, retrospective analysis of 181 of 244 patients with cerebral complications among 2523 surgical cases of infective endocarditis of the Japanese Association of Thoracic Surgery (JATS).

\section{Patients and methods}

We sent a questionnaire to 600 centers belonging to the JATS and received replies from 261 centers, including 174 departments with 2523 patients having cardiac operations for infective endocarditis. A total of 244 patients had associated cerebral complications, and 181 of them were analyzed in detail. The questionnaire consisted of two parts: (1) Each center was asked for a summary of the number and outcome of patients with infective endocarditis according to the types of infective endocarditis ${ }^{1}$ (active/healed and native valve/prosthetic valve) and the presence of cerebral complications; (2) the other portion inquired about each patient with cerebral complications, asking for details such as age, gender, atrial fibrillation, anticoagulant therapy, diseased valve, organism, effectiveness of antimicrobial therapy, reason for early cardiac operation, interval between the onset of symptoms and the cardiac operation, type of cerebral complication, cerebral aneurysm, prior cerebral surgery, severity, influence of operation on cerebral damage, and outcome.

Analyses and statistics. The difference in mortality between the group without cerebral complications and the group with cerebral complications was tested for signifi- cance by $\chi^{2}$ analysis. A diseased valve and an organism were summarized as characteristics of the patients having associated cerebral complications. The type and timing of cerebral disease were documented. To study the influence of cardiac surgery on preoperative cerebral complications, we analyzed the interval between the onset of cerebral complications and performance of the cardiac operation, as well as other preoperative variables. The effectiveness of antimicrobial therapy was ranked in three grades $(1=$ ineffective, 2 = effective, and $3=$ well controlled). Also, the severity of cerebral complications was ranked $(1=$ mild, $2=$ moderate, and $3=$ severe). Indications for early cardiac surgery included ineffectiveness of antimicrobial therapy, vegetations, and uncontrolled congestive heart failure. Cerebral angiographic examination was done in $58.8 \%$ of the patients with cerebral hemorrhage. A correlation between the interval and the exacerbation of cerebral complications was evaluated by means of the Spearman rank correlation coefficient. The intervals were then classified in several groups, and a variability between the groups for the exacerbation was estimated by Scheffe's $\mathrm{F}$ procedure for post-hoc comparisons, according to the Kruskal-Wallis test. To analyze the risk factors affecting exacerbation of cerebral complications, we expressed preoperative variables as mean \pm standard error. The difference between the groups with and without exacerbation was tested for significance by the unpaired $t$ test, and incidence was expressed as percentage of patients having the variable compared with the entire group of patients and then compared by $\chi^{2}$ analysis. Moreover, all variables and incidence (transformed to continuous variables) were estimated by stepwise regression analysis. Statistical significance was accepted at a $p$ level of $<0.05$. These analyses were done with the Stat View system (Abacus Concepts, Inc., Berkeley, Calif.).

\section{Results}

Summary of all patients with infective endocarditis. In total, 2523 patients having infective endocarditis were treated surgically in 174 centers of JATS. Of all the patients, $893(35.4 \%)$ had active native valve endocarditis, $1317(52.2 \%)$ had healed native valve endocarditis, and $315(12.5 \%)$ had prosthetic valve endocarditis. Operative mortality rate was $13.5 \%$ in those with active endocarditis, $4.0 \%$ in those with healed endocarditis, and $33.3 \%$ in those with prosthetic valve endocarditis. On the other hand, 244 patients, $9.7 \%$ of all patients with infective endocarditis, had associated cerebral complications. A total of 1080 (44.3\%) had active endocarditis, $96(39.3 \%)$ had healed endocarditis, and 40 
Table I. Summary of 2523 patients with infective endocarditis

\begin{tabular}{|c|c|c|c|c|c|c|}
\hline & \multicolumn{2}{|c|}{$\begin{array}{l}\text { Without cerebral } \\
\text { complications }\end{array}$} & \multicolumn{2}{|c|}{$\begin{array}{l}\text { With cerebral } \\
\text { complications }\end{array}$} & \multicolumn{2}{|c|}{ Total } \\
\hline & $\begin{array}{c}\text { No. of } \\
\text { patients }\end{array}$ & $\% H D$ & $\begin{array}{c}\text { No. of } \\
\text { patients }\end{array}$ & $\% H D$ & $\begin{array}{c}\text { No. of } \\
\text { patients }\end{array}$ & $\% H D$ \\
\hline ANVE & 784 & 13.4 & 108 & 13.9 & 893 & 13.5 \\
\hline HNVE & 1220 & 4.1 & 96 & 3.1 & 1317 & 4.0 \\
\hline PVE & $\underline{275}$ & 32.7 & 40 & 37.5 & 315 & 33.3 \\
\hline Total & 2279 & 10.8 & 244 & 13.5 & 2523 & 11.0 \\
\hline
\end{tabular}

$H D$, Hospital death; $A N V E$, active native valve endocarditis; $H N V E$, healed native valve endocarditis; $P V E$, prosthetic valve endocarditis.

Table II. Diseased valve in 244 patients

\begin{tabular}{lrr}
\hline & No. & $\%$ \\
\hline Aortic & 126 & 55.5 \\
Mitral & 113 & 49.8 \\
Tricuspid & 3 & 1.3 \\
Pulmonary & 3 & 1.3 \\
\hline
\end{tabular}

$(16.4 \%)$ had prosthetic valve endocarditis. The mortality rates of the patients with cerebral complications were $13.9 \%$ (active endocarditis), 3.1\% (healed endocarditis), and $37.5 \%$ (prosthetic valve endocarditis). No differences in mortality were detected between the group without cerebral complications and the group with cerebral complications (Table I).

Characteristics of patients having cerebral complications. Diseased valves in 244 patients having cerebral complications included the following: aortic valve, 126 (55.5\%); mitral valve, 113 (49.8\%); tricuspid valve, $3(1.3 \%)$, and pulmonary valve, 3 (1.3\%) (Table II). In 181 patients of 244 having infective endocarditis with cerebral complications, organisms were detected as follows: gram-positive cocci in 133 (73.5\% [Streptococcus in 85, Staphylococcus in 32]), gram-negative in $18(9.9 \%$ ) [Enterococcus in 5, Escherichia coli in 3], fungus in 11 $(6.1 \%)$ [Candida in 8$]$, and unknown in $19(10.5 \%)$ (Table III).

Cerebrovascular disease as the complication in patients with infective endocarditis. Details of cerebrovascular disease were analyzed in 181 patients of 244 who had infective endocarditis with cerebral complications. The types of cerebral complication were as follows: cerebral infarction in $117(64.6 \%)$, cerebral bleeding in $57(31.5 \%)$, cerebral abscess in $5(2.8 \%)$, and meningitis in 2 $(1.1 \%)$. Cerebral infarction occurred before the operation in 112, during the operation in 2, and after the operation in 3 . Hospital mortality rates
Table III. Organism in 181 patients

\begin{tabular}{|c|c|c|}
\hline & No. & $\%$ \\
\hline Gram positive & 133 & 73.5 \\
\hline Streptococcus & 85 & 63.9 \\
\hline Staphylococcus & 32 & 24.1 \\
\hline Others & 16 & 12.0 \\
\hline Gram negative & 18 & 9.9 \\
\hline Enterococcus & 5 & 27.8 \\
\hline Escherichia coli & 3 & 16.7 \\
\hline Others & 10 & 55.6 \\
\hline Fungus & 11 & 6.1 \\
\hline Candida & 8 & 72.7 \\
\hline Others & 3 & 27.3 \\
\hline Unknown & 19 & 10.5 \\
\hline
\end{tabular}

were $21.4 \%$ in patients with preoperative onset, $100 \%$ in those with onset during the operation, and $33.3 \%$ in those with postoperative onset. Cerebral bleeding occurred before the operation in 34 , during the operation in 8 , and after the operation in 15 . Hospital mortality rates were $17.6 \%$ in patients with preoperative onset, $50.0 \%$ in those with perioperative onset, and $73.3 \%$ in those with postoperative onset.

Influence of cardiac surgery on preoperative cerebral infarction. In 11 patients, the cardiac operation was performed within 24 hours after the onset of cerebral infarction (mortality rate 66.3\%) (Figs. 1 and 2). The operation was performed between 2 and 7 days later in 16 patients (mortality rate $31.3 \%$ ), between 8 and 14 days later in 12 patients (mortality rate $16.7 \%$ ), between 15 and 21 days later in 10 patients (mortality rate $10.0 \%$ ), between 22 and 28 days later in 19 patients (mortality rate $26.3 \%$ ), and more than 4 weeks later in 43 patients (mortality rate $7.0 \%$ ). The rates of exacerbation of cerebral complications, including related death, were as follows: $45.5 \%$ in patients who were operated on within 24 hours, $43.8 \%$ in those operated on within 2 to 7 


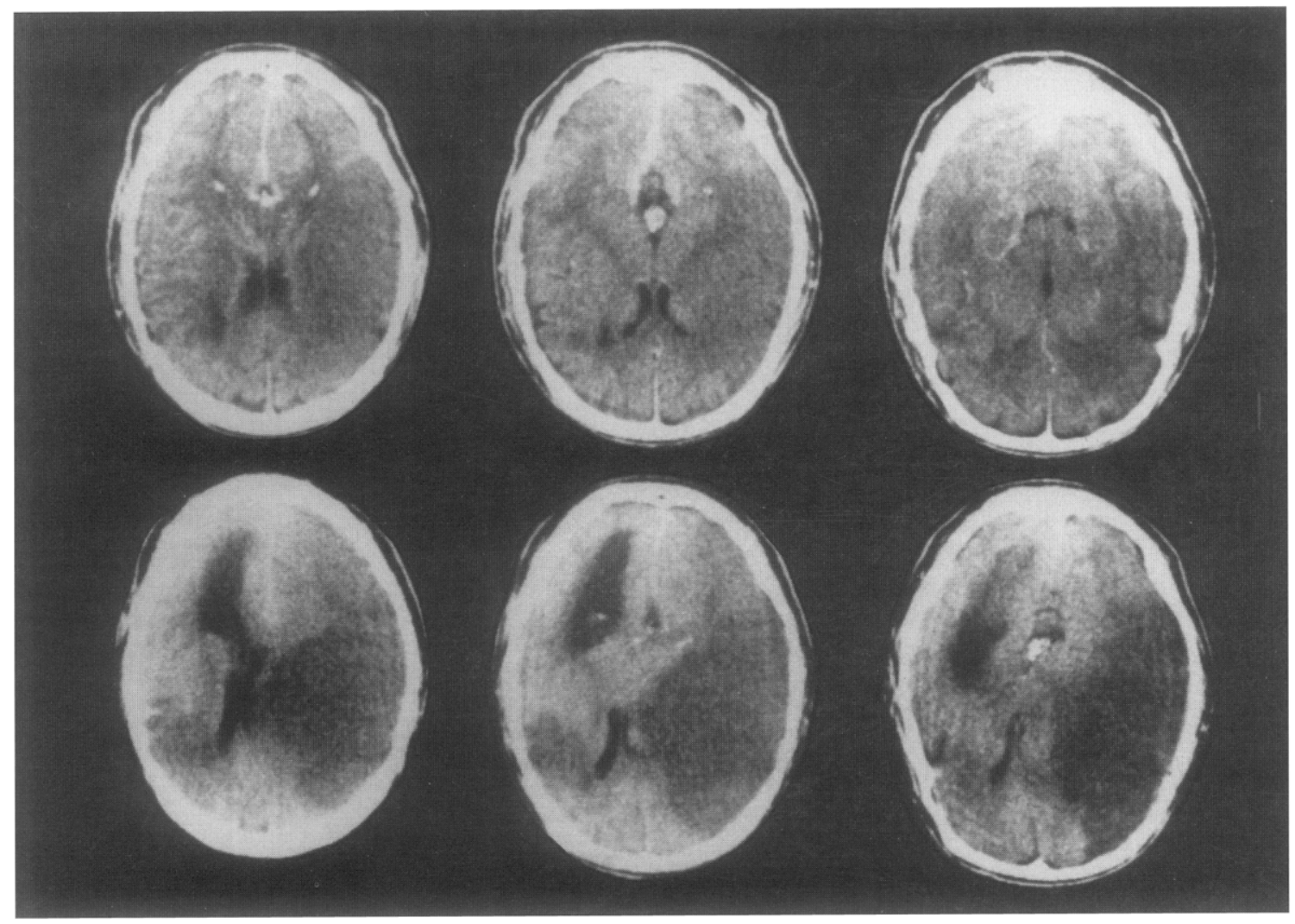

Fig. 1. Computed tomographic scans of a patient with right middle cerebral artery infarction resulting from infective endocarditis. This patient underwent a Bentall-type operation for graft infection on the same day, resulting in massive brain swelling, and died 3 days later. Top row, Preoperative computed tomographic scans; bottom row, postoperative scans.

days, $16.7 \%$ for those operated on within 8 to 14 days, $10.0 \%$ for those operated on within 15 to 21 days, $10.5 \%$ for those operated on within 22 to 28 days, and $2.3 \%$ for those operated on more than 4 weeks later (Fig. 3). A significant correlation existed between the interval and the exacerbation of cerebral complications by the Spearman rank correlation coefficient (tied $p=0.008$ ). When the intervals were classified in three groups (within 7 days, 8 to 14 days, and 15 to 28 days), a significant difference for the exacerbation was confirmed by post-hoc comparisons $(p=0.022)$ between the group within 7 days and the group treated at 15 to 28 days (Fig. 4).

Preoperative risk factors affecting exacerbation of cerebral complications were analyzed statistically. The significant variables were severity of cerebral complication $(p=0.006)$, intervals $(p=0.012)$, and uncontrolled congestive heart failure as an indication for cardiac surgery $(p=0.014)$ (Table IV). The rate of ineffectiveness of antimicrobial therapy was two times greater in the group with exacerbation than in the group without exacerbation, although the difference was not verified statistically.

Influence of cardiac surgery on preoperative cerebral hemorrhage. One patient underwent a cardiac operation within 24 hours after the onset of cerebral hemorrhage and died of cerebral damage. In another patient the cardiac operation was performed successfully 5 days later, with prior surgical treatment for cerebral aneurysm. In five patients the cardiac operation was performed between 15 and 21 days later (mortality rate 20.0\%) (Fig. 5). The operation was done between 22 and 28 days later in six patients with no mortality and more than 4 weeks later in 21 patients (mortality rate 19.0\%). No exacerbation of cerebral complications occurred in patients who underwent their cardiac operation between 2 and 28 days. Nevertheless, exacerbations did occur, at a rate of $19.0 \%$, in patients who were operated on more than 4 weeks later (Figs. 6 and 7). The group having exacerbations of symptoms contained only five patients, and there was no correla- 


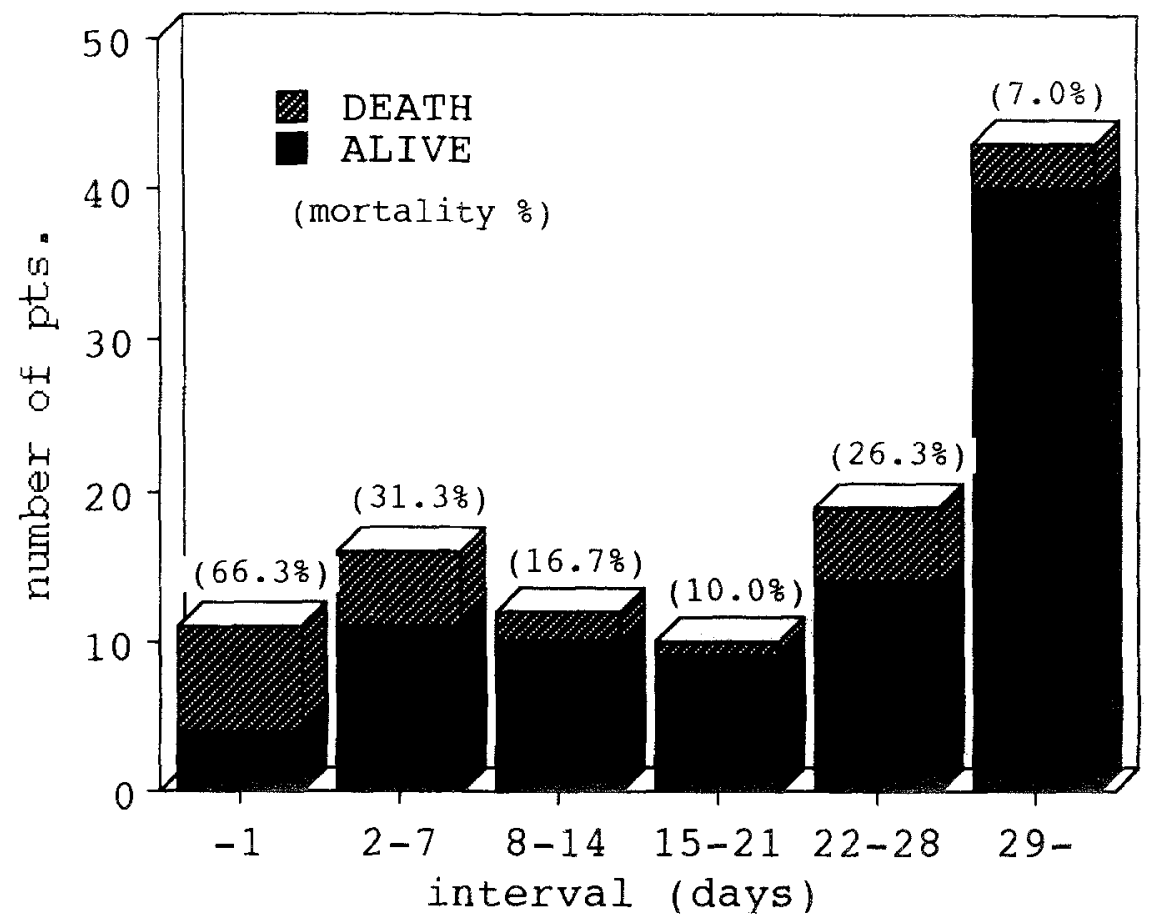

Fig. 2. Distribution of the patients and hospital mortality according to intervals from the onset of cerebral infarction until the cardiac operation.

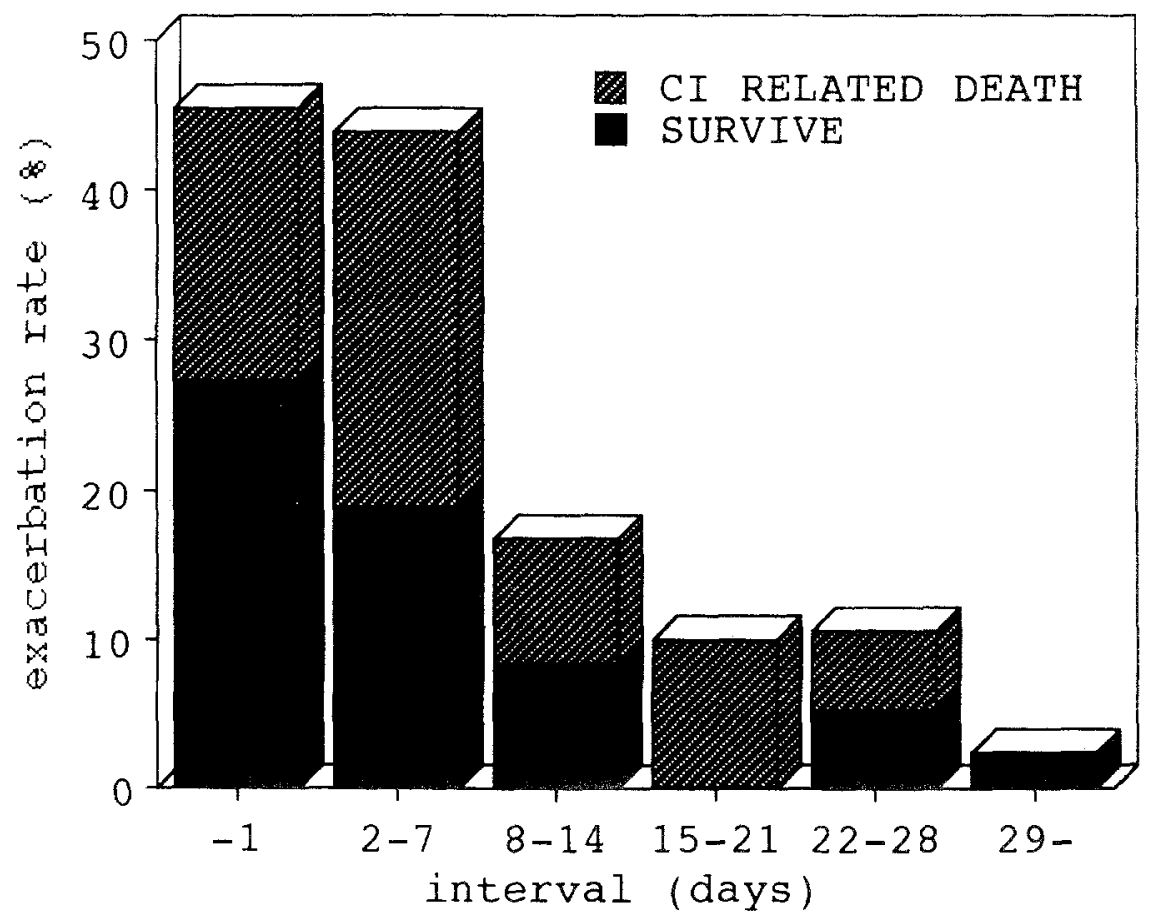

Fig. 3. Exacerbation rate of cerebral damage including death related to cerebral injury according to the intervals from the onset of cerebral infarction $(C I)$ until the cardiac operation. 


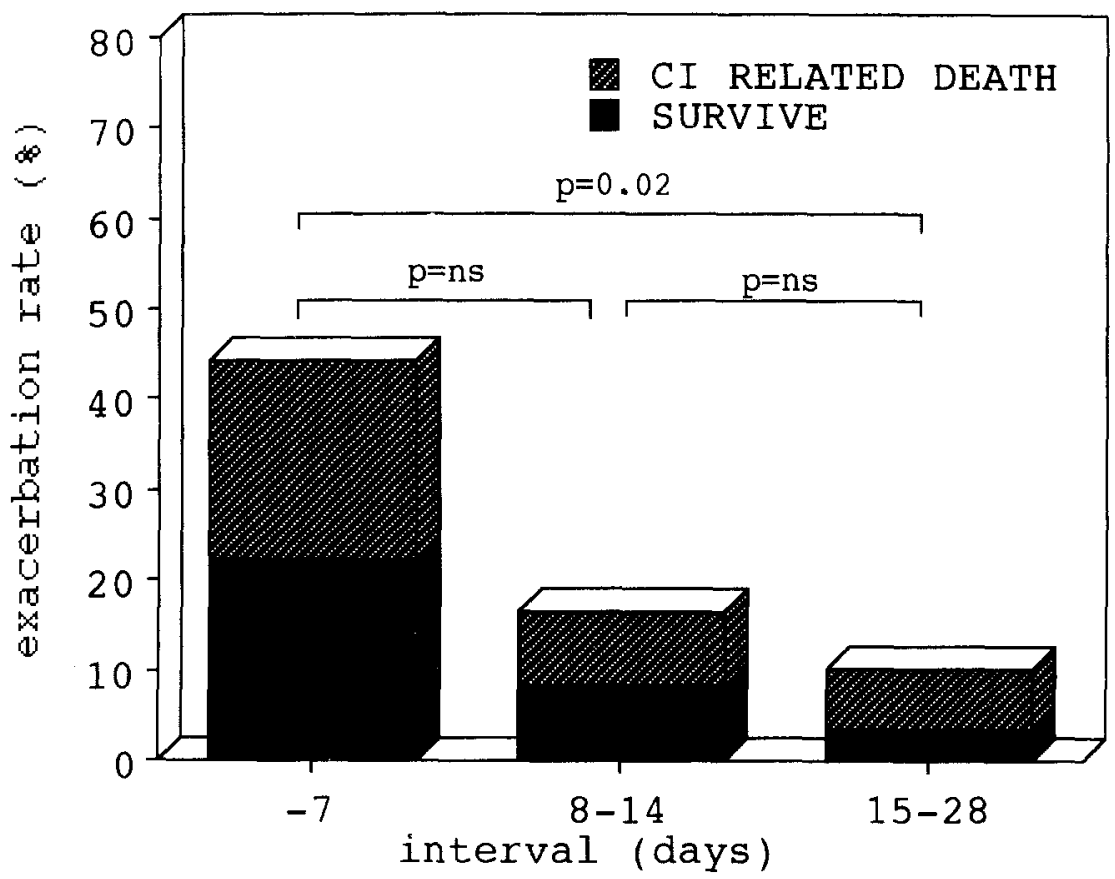

Fig. 4. Correlation between the interval from the onset of cerebral infarction (CI) until the cardiac operation and the exacerbation of cerebral complications. When the intervals were classified into three groups, a significant difference in exacerbations was confirmed by post-hoc comparisons between the group operated on within 7 days and the group operated on within 15 to 28 days. $n s$, Not significant.

tion between the interval and the exacerbation of cerebral complications.

All of the patients with exacerbation and $76.5 \%$ without exacerbation had cerebral arterial aneurysm before the operation, although a cerebral angiographic examination was done in $58.8 \%$ of the patients with cerebral hemorrhage. No one with exacerbation had received surgical treatment for cerebral aneurysm before the cardiac operation, whereas $27.6 \%$ without exacerbation had undergone an operation for cerebral disease. The variable influencing exacerbation, according to stepwise regression analysis $(p=0.013)$, was atrial fibrillation (Table V).

\section{Discussion}

This study consisted of a questionnaire to the centers belonging to the JATS. The 181 patients gleaned from 244 patients with cerebral complications undergoing surgical treatment for infective endocarditis were able to be analyzed in detail. Several groups have tried to assess the effect of the timing of surgical therapy on patients with recent neurologic injuries. ${ }^{5,8-10}$ However, because of the limited number of cases, the appropriate timing of surgical intervention has not been addressed adequately. This study was based on a sufficient number for discussion of the effect of cardiac operations on patients with cerebral complications.

Characteristics of patients with cerebral complications. It has been reported that $20 \%$ to $30 \%$ of patients with infective endocarditis may have cerebrovascular complications. ${ }^{6,8,12-17}$ In this review of 2523 surgical cases of infective endocarditis, $9.7 \%$ of the total $(12.1 \%$ of patients having active native valve endocarditis, $7.3 \%$ of those having healed native valve endocarditis, and $12.7 \%$ of those having prosthetic valve endocarditis) had associated cerebral complications. Cerebral ischemia was present in $64.6 \%$ and hemorrhage in $31.5 \% .^{6,18}$ Staphylococcus aureus was the most virulent organism involved in the central nervous system., 6, 7,18-20 However, in this study of cerebral complications, Streptococcus was the most common organism followed by Staphylococcus. This trend mirrors findings in the whole population of patients with infective endocarditis. ${ }^{1}$ In $42 \%$ of the patients with cerebral complications, antibiotics were ineffective.

Mortality of cardiac surgery in patients having infective endocarditis with cerebral complications compared with that of patients without cerebral complications. The operative outcome would be influenced by the organism, the intensity of cardiac 


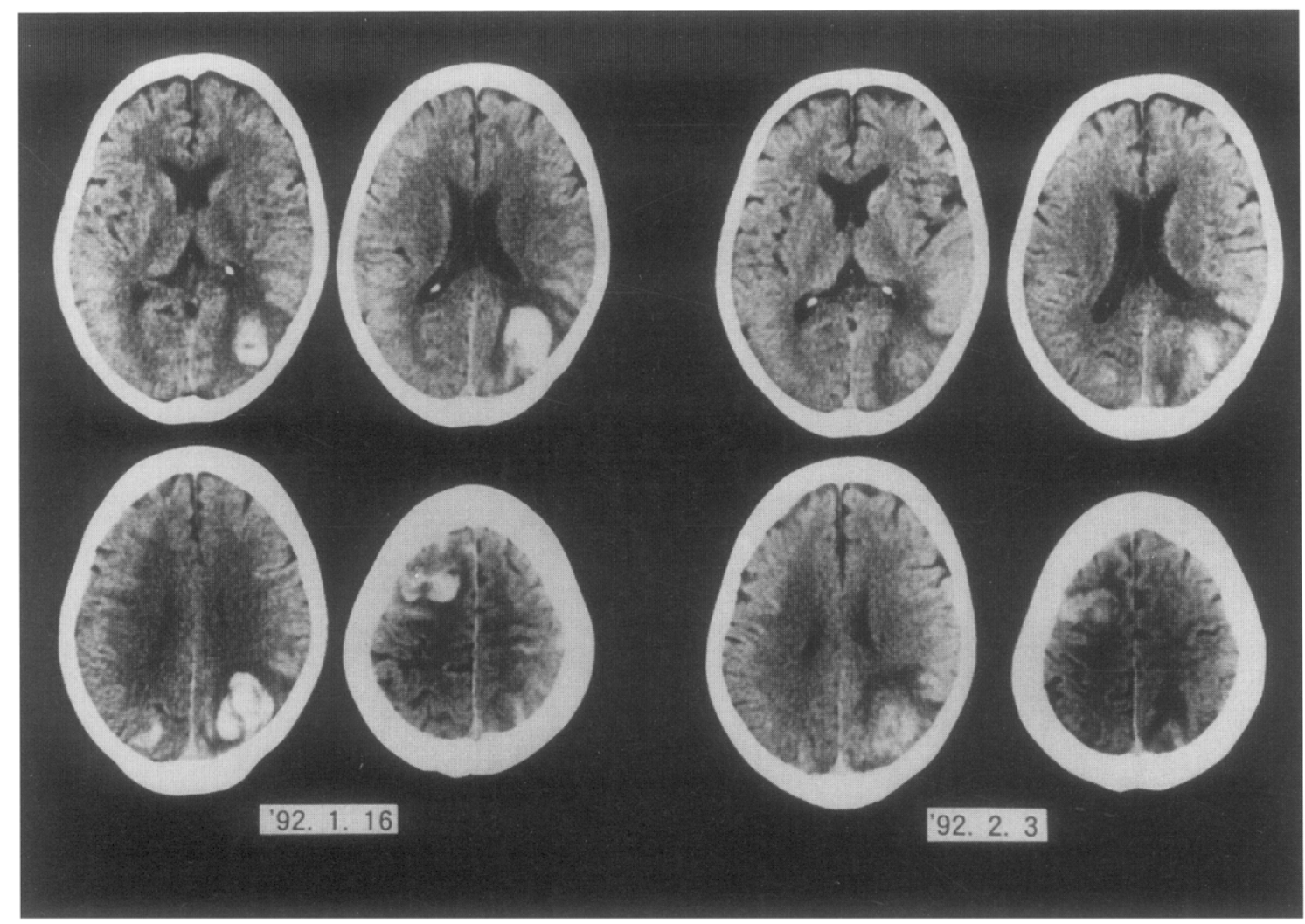

Fig. 5. Computed tomographic scans of a patient with cerebral hemorrhage resulting from infective endocarditis. This patient underwent mitral valve rereplacement 15 days after cerebral hemorrhage without any complications. Left, Preoperative computed tomographic scan; right, postoperative scan.

Table IV. Analysis of risk factors affecting exacerbation of cerebral complications in 68 patients who had cerebral infarction within 4 weeks

\begin{tabular}{lccc}
\hline & \multicolumn{3}{c}{ Exacerbation } \\
\cline { 2 - 4 } & With $(n=17)$ & Without $(n=51)$ & Significance \\
\hline Continuous variables (mean \pm SE) & & & \\
Age (yr) & $45.5 \pm 3.7$ & $40.4 \pm 2.1$ & $p=0.237$ \\
Effect of AM (1/2/3) & $1.6 \pm 0.2$ & $2.0 \pm 0.1$ & $p=0.126$ \\
Severity of CC (1/2/3) & $2.2 \pm 0.2$ & $1.7 \pm 0.1$ & $p=0.006$ 市 \\
Interval (days) & $7.9 \pm 2.2$ & $15.1 \pm 1.4$ \\
Nominal variables (\%) $\$$ & & & \\
Gender (male) & 47.1 & 52.9 & $p=0.012$ \\
Atrial fibrillation & 17.6 & 25.5 & $p=0.509$ \\
Anticoagulant therapy & 35.3 & 23.5 & $p=0.341$ \\
Aortic lesion & 70.6 & 51.0 & $p=0.159$ \\
Mitral lesion & 41.1 & 62.7 & $p=0.119$ \\
Ineffectiveness of AM & 41.2 & 20.0 & $p=0.083$ \\
Vegetation & 70.6 & 84.0 & $p=0.227$ \\
Congestive heart failure & 76.5 & 42.0 & $p=0.014$ \\
\end{tabular}

$S E$, standard error; $A M$, antimicrobial therapy; CC, cerebral complication. Underlining showed the significant factor by $t$ or $\chi^{2}$ test. ${ }^{*} p$ Values for continuous variables were determined by the unpaired $t$ test.

$\dagger$ Significant $(p=0.017)$ by stepwise regression analysis.

$\ddagger p$ Values for nominal variables were determined by the $\chi^{2}$ test. 


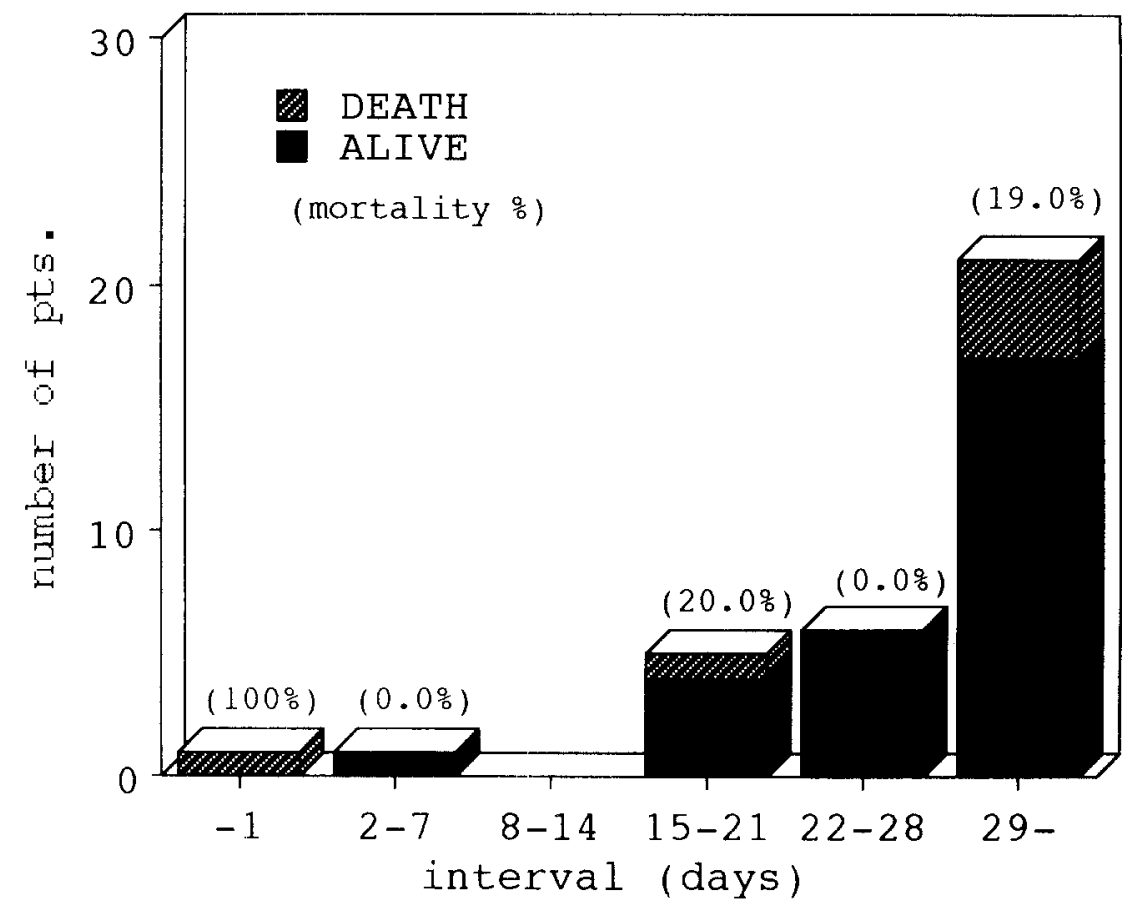

Fig. 6. Distribution of the patients and hospital mortality according to the intervals from the onset of cerebral hemorrhage until the cardiac operation.

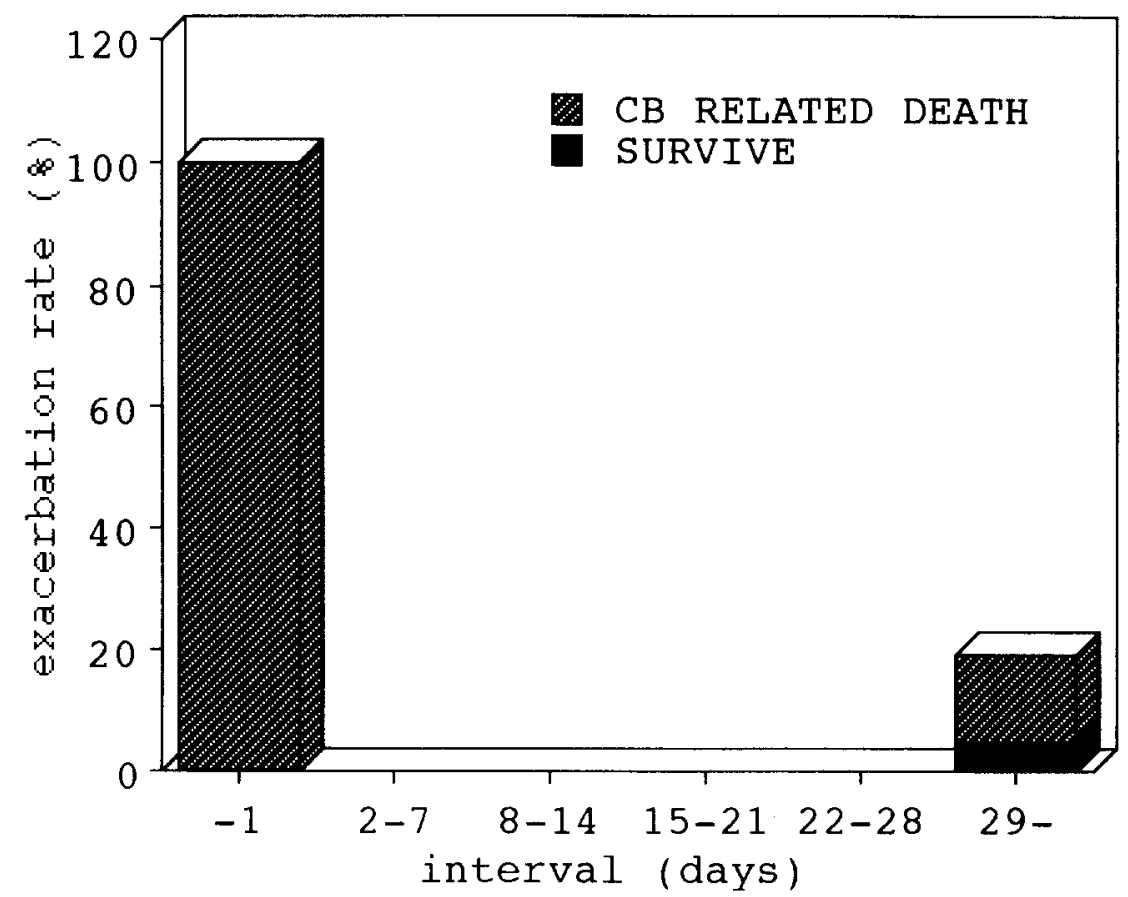

Fig. 7. Exacerbation rate of cerebral damage including death related to cerebral injury $(C B)$ according to the intervals from the onset of cerebral hemorrhage until the cardiac operation. 
Table V. Analysis of risk factors affecting exacerbation of cerebral complications in 34 patients who had cerebral hemorrhage preoperatively

\begin{tabular}{|c|c|c|c|}
\hline & \multicolumn{3}{|c|}{ Exacerbation } \\
\hline & With $(n=5)$ & Without $(n=29)$ & Significance \\
\hline \multicolumn{4}{|c|}{ Continuous variables (mean $\pm \mathrm{SE})^{*}$} \\
\hline Age (yr) & $37.6 \pm 3.4$ & $38.1 \pm 3.2$ & $p=0.953$ \\
\hline Effect of $\mathrm{AM}(1 / 2 / 3)$ & $2.0 \pm 0.4$ & $2.1 \pm 0.1$ & $p=0.827$ \\
\hline Severity of CC $(1 / 2 / 3)$ & $2.4 \pm 0.2$ & $2.0 \pm 0.1$ & $p=0.296$ \\
\hline Interval (days) & $178 \pm 111$ & $80.5 \pm 25$ & $p=0.196$ \\
\hline \multicolumn{4}{|l|}{ Nominal variables $(\%) \dagger$} \\
\hline Gender (male) & 60.0 & 65.5 & $p=0.812$ \\
\hline Atrial fibrillation & 40.0 & 13.8 & $\mathrm{p}=0.156+$ \\
\hline Anticoagulant therapy & 20.0 & 27.6 & $p=0.723$ \\
\hline Aortic lesion & 80.0 & 58.6 & $p=0.364$ \\
\hline Mitral lesion & 20.0 & 48.3 & $p=0.110$ \\
\hline Ineffectiveness of AM & 40.0 & 20.7 & $p=0.347$ \\
\hline Vegetation & 40.0 & 58.6 & $p=0.440$ \\
\hline Congestive heart failure & 60.0 & 65.6 & $p=0.812$ \\
\hline Cerebral aneurysm & 100 & 76.5 & $p=0.348$ \\
\hline Cerebral operation & 0.0 & 27.6 & $p=0.179$ \\
\hline
\end{tabular}

$S E$, Standard error; AM, antibiotics; $\mathrm{CC}$, cerebral complication.

" $p$ Values for continuous variables were determined by the unpaired $t$ test.

$t p$ Values for nominal variables were determined by the $X^{2}$ test.

$\ddagger$ Significant $(p=0.013)$ by stepwise regression analysis.

dysfunction, the presence of annular abscess, and so forth. Irrespective of these factors, the mortality rate in patients with cerebral complications was no higher than that in patients without cerebral complications in this study (13.5\% versus $11.0 \%)$. Also, the mortality rate in the patients with cerebral hemorrhage was no higher than that in patients with cerebral infarction $(20.0 \%$ versus $20.7 \%$ ). Pruitt and associates $^{21}$ reported that the mortality rate for 84 patients with neurologic complications was $58 \%$, in contrast to the $20 \%$ mortality rate among the 134 patients without neurologic involvement. Operative mortality for early valve replacement ranges from $10 \%$ to $37 \%$. 2, 7, 20, 22-26 The preoperative condition of the patients with cerebral complications, especially of those requiring early operation, would be more severe. Our results showed that preoperative cerebral complications caused a substantial number of deaths. It is clear that the timing of the cardiac operation affects the outcome in patients with cerebral infarction.

Influence of cardiac surgery on preoperative cerebral infarction. The major purpose of this study is to clarify how long to wait before performing a cardiac operation after the onset of cerebral complications in patients in whom early cardiac repair would be advisable. In $43.8 \%$ of the patients requiring a cardiac operation within 7 days after cerebral infarction, cerebral damage was exacerbated. The exacerbation rate decreased gradually with the timing of the operation and, in the group operated on after 28 days, it was $2.3 \%$.

According to these data, a cardiac operation can be done safely after 4 weeks; after a delay of more than 2 weeks, the exacerbation rate will be around $10 \%$. If the natural history of the patient receiving medication is expected to be very bad, surgical repair might be appropriate even in a week. Moreover, if the patient requires an early operation because of uncontrolled heart failure or if the preoperative cerebral infarction is severe, the risk of surgical treatment would be higher than expected according to timing of the operation. Ineffectiveness of antimicrobial therapy may affect cerebral damage, although such an effect was not verified statistically.

Influence of cardiac surgery on preoperative cerebral hemorrhage. The number of patients who underwent a cardiac operation within 4 weeks after cerebral infarction was large, whereas the number having the operation within 4 weeks after hemorrhage might be too small (13 patients) to allow us to evaluate the influence of the passage of time before heart surgery. However, heart surgery within 24 hours after cerebral hemorrhage has a high risk of causing fatal cerebral damage. Although no one of 
the 11 patients who underwent cardiac surgery between 15 days and 28 days after cerebral hemorrhage had exacerbation of cerebral damage during the operation, $19.0 \%$ of 21 patients operated on more than 4 weeks later had an exacerbation. These data suggest that there is some risk of progression of cerebral damage 15 days and even 4 weeks after the hemorrhage, regardless of the timing of the operation. The severity of cerebral complications and the ineffectiveness of antimicrobial therapy may affect cerebral damage, although this effect was not verified statistically. The incidence of clinically apparent mycotic aneurysm in patients with bacterial endocarditis was reported as $2 \%$ to $10 \% .{ }^{13-16,19,27,28} \mathrm{In}$ our study, a cerebral aneurysm was noticed in about $80 \%$ of the patients with cerebral hemorrhage who received cerebral angiograms, and surgical treatment for cerebral aneurysm or hemorrhage would be expected to reduce the risk of cerebral damage during cardiac operations. To decrease the tendency toward hemorrhage, reduced heparinization in conjunction with a heparin-coated pump system would be useful during cardiac operations.

\section{Conclusion}

From a multi-center retrospective study, 181 patients with infective endocarditis and cerebral complications were analyzed in detail. The rate of exacerbation of cerebral complications decreased to $10 \%$ in patients who underwent surgical treatment more than 15 days after cerebral infarction and to $2.3 \%$ in those operated on more than 4 weeks later. Preoperative risk factors were severity of cerebral complications, interval from onset of symptoms to operation, and uncontrolled heart failure as the indication for cardiac surgery. More than 15 days after cerebral hemorrhage, the risk of the progression of cerebral damage is still significant, and this risk persists even 4 weeks later.

We are grateful to all the institutions belonging to the JATS for providing data for this manuscript.

\section{REFERENCES}

1. Manhas DR, Mohri H, Hessel EA, Merendino KA. Experience with surgical management of primary infective endocarditis: a collected review of 139 patients. Am Heart J 1972;84:738-47.

2. Boyd AD, Spencer FC, Isom OW, et al. Infective endocarditis: an analysis of 54 surgically treated patients. J Thorac Cardiovasc Surg 197;73:23-30.

3. Prager RL, Maples MD, Hammon JW, Friensinger GC,
Bender HW. Early operative intervention in aortic bacterial endocarditis. Ann Thorac Surg 1981;32:347-50.

4. Osler W. The Goulstonian lectures on malignant endocarditis. BMJ 1885;1:467-70.

5. Cukingnan RA, Carey JS, Wittig JH, Cimochowski GE. Early valve replacement in active infective endocarditis. J Thorac Cardiovasc Surg 1983;85: 163-73.

6. Lerner PI. Neurologic complications of infective endocarditis. Med Clin North Am 1985;69:385-98.

7. D'Agostino RS, Miller DC, Stinson EB, et al. Valve replacement in patients with native valve endocarditis: What really determines operative outcome? Ann Thorac Surg 1985;40:429-38.

8. Zisbrod Z, Rose DM, Jacobowitz IJ, Kramer M, Acinapura AJ, Cunningham JN Jr. Results of open heart surgery in patients with recent cardiogenic embolic stroke and central nervous system dysfunction. Circulation 1987;76(Suppl):V109-12.

9. Maruyama M, Kuriyama Y, Sawada T, Yamaguchi T, Fujita $T$, Omae $T$. Brain damage after open heart surgery in patients with acute cardioembolic stroke. Stroke 1989;20:1305-10.

10. Matsushita K, Kuriyama Y, Sawada T, et al. Hemorrhagic and ischemic cerebrovascular complications of active infective endocarditis of native valve. Eur Neurol 1993;33:267-74.

11. Tunkel AR, Kaye D. Neurologic complications of infective endocarditis. Neurol Clin 1993;11:419-40.

12. Harrison JJG, Hampton JR. Neurologic presentation of bacterial endocarditis. BMJ 1967;2:148-51.

13. Ziment I. Nervous system complications of bacterial endocarditis. Am J Med 1969;47:593-607.

14. Jones HR, Siekert RG, Gerachi JE. Neurologic manifestations of bacterial endocarditis. Ann Intern Med 1969;71:21-8.

15. McNeel D, Evans RA, Ory EM. Angiography of cerebral mycotic aneurysms. Acta Radiol 1969;9: 407-12.

16. Katz RI, Goldberg HI, Selzer ME. Mycotic aneurysm. Arch Intern Med 1974;134:939-42.

17. Jones HR Jr, Siekert RG. Neurological manifestations of infective endocarditis. Brain 1989;112:1295-315.

18. Hart RG, Foster JW, Luther MF, Kanter MC. Stroke in infective endocarditis. Stroke 1990;21:695-700.

19. Hart RG, Kagan-Hallet K, Joerns SE. Mechanisms of intracranial hemorrhage in infective endocarditis. Stroke 1987;18:1048-56.

20. Govier AV, Reves JG, Mckay RD, et al. Factors and their influence on regional cerebral blood flow during nonpulsatile cardiopulmonary bypass. Ann Thorac Surg 1984;38:592-600.

21. Pruitt AA, Rubin RH, Karchmer AW, et al. Neurologic complications of bacterial endocarditis. Medicine 1978;57:329-43.

22. Richardson JV, Karp RB, Kirklin JW, Dismukes WE. 
Treatment of infective endocarditis: a 10-year experience. Circulation 1978;58:589-97.

23. Wilson WR, Danielson GK, Guiliani ER, Washington JA II, Jaumin PM, Geraci JE. Valve replacement in patients with active infective endocarditis. Circulation 1978;58:585-8.

24. Stinson EB. Surgical treatment of infective endocarditis. Prog Cardiovasc Dis 1979;22:145-68.

25. Young JB, Welton DE, Raizner AE, et al. Surgery in infective endocarditis. Circulation 1979;60(Suppl)I77-81.
26. Paschalis C, Pugsley W, John R, Harrison MJG. Rate of cerebral embolic events in relation to antibiotic and anticoagulant therapy in patients with bacterial endocarditis. Eur Neurol 1990;30:87-9.

27. Roach MR, Drake CG. Ruptured cerebral aneurysms caused by microorganisms. 1965;273:240-4.

28. Cantu RC, LeMay M, Wilkinson HA. The importance of repeated angiography in the treatment of micoticembolic intracranial aneurysms. J Neurosurg 1966;25: 189-93. 